\title{
Reasons for the Use of Health Care in Elderly Persons Undergoing Consultation in the University Clinic of Internal Medicine and Medical Oncology of the Hubert Koutoukou Maga National Hospital and University Center (CNHU-HKM) of Cotonou
}

\author{
Angèle Azon-Kouanou*, Mahougnon Jean-Christ Alix Aïdasso, Mahoutin Semassa Ghislain Missiho, \\ Eugénie Dansou, Faustin Havugimana Karuhije, Janvier Kitumaini Kondoli, Richard Oba, \\ Kouessi Anthelme Agbodande, Yves Morel Sokadjo, Djimon Marcel Zannou, Fabien Houngbé
}

Internal Medicine Department of Hubert Koutoukou Maga National Hospital and University Center in Cotonou (CNHU-HKM), Cotonou, Benin

Email: *angele.azonkouanou@gmail.com

How to cite this paper: Azon-Kouanou, A., Aïdasso, M.J.-C.A., Missiho, M.S.G., Dansou, E., Karuhije, F.H., Kondoli, J.K., Oba, R., Agbodande, K.A., Sokadjo, Y.M., Zannou, D.M. and Houngbé, F. (2020) Reasons for the Use of Health Care in Elderly Persons Undergoing Consultation in the University Clinic of Internal Medicine and Medical Oncology of the Hubert Koutoukou Maga National Hospital and University Center (CNHU-HKM) of Cotonou. Open Journal of Internal Medicine, 10, 280-287. https://doi.org/10.4236/ojim.2020.103029

\section{Received: July 17, 2020}

Accepted: September 18, 2020

Published: September 21, 2020

Copyright $\odot 2020$ by author(s) and Scientific Research Publishing Inc. This work is licensed under the Creative Commons Attribution International License (CC BY 4.0).

http://creativecommons.org/licenses/by/4.0/

\begin{abstract}
Introduction: The progressive ageing of the population from southern Sahara is leading to an increase in health needs among the elderly. The purpose of this study was to output an overview about the reasons why the elderly come for consultation in the internal medicine department of the HKM-NHUC in Cotonou. Methodology: This was a retrospective, descriptive, and analytical study, which included all patients aged 65 years and over, who came for the first time for consultation in the Internal Medicine Department of the CNHUHKM between January $1^{\text {st }}$ and December $31^{\text {st }}$, 2017. Results: Among the 680 new patients received in internal Medicine consultations during the study period, 118 people were aged 65 and over, representing a hospital frequency of $17.35 \%$. The sex ratio was 0.9 with a mean age of $73 \pm 7$ years. Hypertension was the main comorbidity of the patients (69\%). Cough (11.3\%) and low back pain $(8.2 \%)$ dominated the reasons for consultation. The three main nosological groups of pathologies were, in descending order, diseases of the osteoarticular system (17.5\%), diseases of the respiratory system (16.5\%) and diseases of the circulatory system (12.4\%). Pneumonia (11.3\%) and lumbosacral spondylarthrosis (10.3\%) were the most frequent pathologies in patients whose health needs remain quite varied. Conclusion: The elderly become gradually
\end{abstract}


an important part of the population in southern Sahara. A better understanding of the health needs of this category of the population is necessary to deal effectively with the health challenges that will accompany this phenomenon.

\section{Keywords}

The Elderly, Reason for Consultation, Internal Medicine

\section{Introduction}

During the past six decades, global life expectancy at birth has increased by 20 years. In other words, from 52 years in 1960, it becomes 72 years in 2017 [1]. Sub-Saharan Africa and Benin in particular, despite a delay, also encounter a change with its life expectancy to 61 years [1]. Therefore, we can guess that there is a significant increase in the proportion of the elderly and demographic estimates predict its rapid growth [2]. Consequently, this demographic situation correlates with a change in the listing of health problems. Actually, the older you are, the more pathology your health faces [3]. In western countries, the main health characteristic of elderly populations is a high prevalence of chronic pathologies [4]. Thus, arthritis/arthritis, depression, cancer, osteoporosis, coronary, pulmonary, and cardiac pathologies are the most common pathologies found in Switzerland [4]. As far as the United States is concerned, the health problems of the elderly are about falls, cognitive decline, heart disease, osteoporosis, respiratory, eye, and cancer pathologies [4] [5]. In sub-Saharan Africa, particularly in Benin, there are no data related to the elderly's health problems in medical consultation. This situation makes complicate the setting of any policy or strategy to address this new challenge. It is in this perspective that this work focuses on the establishment of an overview about the care requests of the elderly in internal medicine consultation at the CNHU-HKM in Cotonou.

\section{Material and Method}

\subsection{Study Population}

The current work is a retrospective, descriptive, and analytical study that took place in the Internal Medicine department of CNHU-HKM in Cotonou, the referral hospital in Benin. The study was carried out from the medical records of patients whose first consultation in the Internal Medicine department was made between January 1 and December 31, 2017. The elderly were defined according to the threshold of 1 "WHO 65 years old. It included patients aged 65 years and over who came for the first time in consultation between January 1 and December 31, 2017. The elderly were defined according to the WHO threshold of 65 years. We did not include patients aged 65 and over, seen in consultation during the study period but whose medical follow-up in the department was prior to 
January 1, 2017.

\subsection{Studied Variables}

The variables studied were socio-demographic variables, chronic disease history variables, clinical information variables, and diagnosis. The various diagnoses were selected by hospital practitioners affiliated to the Internal Medicine Department of the CNHU-HKM of Cotonou on the basis of specific clinical and paraclinical criteria. The diagnosis was qualified as indeterminate when explorations had not led to a formal diagnosis. The classifications of the different conditions by nosological group were done following the International Classification of Diseases, $10^{\text {th }}$ revision (ICD-10).

\subsection{Statistical Analysis Process}

The data were collected with a survey form from patients' medical records. After verification and coding, statistical analysis of the data was done using Epidata Analysis software. In the univariate analysis, we output frequencies and proportions of qualitative variable modalities and concerning quantitative variables, we have the means and standard deviations. The test of $\mathrm{Khi}^{2}$ was used to check the plausible relation between two categorical variables. A value of $p<0.05$ was considered significant.

\section{Results}

\subsection{General Characteristics}

Between 1 January and 31 December 2017, 680 new patients were received in Internal Medicine consultations, including 118 people aged 65 and over, representing a hospital frequency of $17.35 \%$. Only the files of 103 patients were found, of which 97 were usable.

Forty-six of the 97 patients were male with a sex ratio of 0.9 . The mean age was $73 \pm 7$ years, with extremes of 65 and 105 years. Sixty-two patients (63.9\%) were aged 65 to 74 years and 35 patients (36.1\%) were 75 years and older. Eighteen patients $(18.55 \%)$ were still professionally active.

\subsection{History of Chronic Illness}

Eighty-six patients (88.65\%) had at least one history of chronic illness and onethird of patients $(33 \%)$ had two or more (Table 1). High blood pressure was the most common history (69\%), followed by diabetes (12.37\%) and obesity $(7.21 \%)$

\subsection{Reasons for Consultation}

The reasons for consultation were varied. Cough was the first clinical symptom (11.3\%), followed by low back pain and routine check-ups (8.2\%). It should be noted that abdominal pain, the $6^{\text {th }}$ most frequent reason for consultation, was statistically more frequent in women than in men (Table 2). 
Table 1. Number of comorbidities per patient.

\begin{tabular}{ccc}
\hline Number of comorbidity & N & $\%$ \\
\hline 0 & 11 & 11.3 \\
1 & 54 & 55.67 \\
2 & 25 & 25.77 \\
3 & 4 & 4.12 \\
$>3$ & 3 & 3.09 \\
Total & 97 & 100 \\
\hline
\end{tabular}

Table 2. Main reasons for consulting patients.

\begin{tabular}{cccccc}
\hline & $\begin{array}{c}\text { Number } \mathbf{n}=97 \\
(\%)\end{array}$ & Sex & \multirow{2}{*}{$\mathbf{p}$} \\
\cline { 3 - 4 } Cough & $11(11.3)$ & 4 & $\mathbf{F}$ & \\
\hline Low back pain & $8(8.2)$ & 3 & 5 & 0.244 \\
Routine consultation & $8(8.2)$ & 4 & 4 & 0.401 \\
Asthenia & $7(7.2)$ & 3 & 4 & 0.895 \\
Dyspnea & $7(7.2)$ & 4 & 3 & 0.649 \\
Abdominal pain & $5(5.2)$ & 0 & 5 & 0.999 \\
Insomnia & $4(4.1)$ & 3 & 1 & 0.025 \\
Pollakiuria & $4(4.1)$ & 2 & 2 & $>0.999$ \\
Bilateral lower limb oedema & $3(3.1)$ & 2 & 1 & $>0.999$ \\
Hiccup & $3(3.1)$ & 3 & 0 & 0.393 \\
\hline
\end{tabular}

\subsection{Nosological Groups of Pathologies of the Elderly}

Diseases of the osteo-articular system and connective tissue were the most frequent nosological group (17.5\%), followed by diseases of the respiratory system $(16.5 \%)$ and the circulatory system (12.4\%). The latter was followed by diseases of the digestive system (8.2\%) and genitourinary tract (6.2\%). Tumors, mental disorders (5.2\% each), diseases of the nervous system (3.1\%), infectious and parasitic diseases (2.1\%), and endocrine diseases (2.1\%) were infrequent. None of these nosological groups was significantly associated with gender.

\subsection{The Main Pathologies of the Elderly}

Pneumonia was the most common condition (11.3\%), followed by lumbosacral spondylarthrosis (10.3\%). In third place was prostatitis (4.1\%) followed by asthma (3.1\%) (Table 3).

\section{Discussion}

Despite a birth rate that remains high and sustained, population ageing is still a reality in sub-Saharan Africa [4]. This ageing is accompanied by an increase in 
Table 3. Proportion of top ten diseases.

\begin{tabular}{cccccc}
\hline & $\begin{array}{c}\text { Number } \mathbf{n}=97 \\
\text { (\%) }\end{array}$ & \multicolumn{3}{c}{ Sex } & p \\
\cline { 3 - 4 } & $11(11.3)$ & 6 & 5 & $>0.999$ \\
Pneumonia & $10(10.3)$ & 5 & 5 & 0.824 \\
Lumbosacral spondylarthrosis & $4(4.1)$ & 4 & 0 & 0.229 \\
Prostatite & $3(3.1)$ & 3 & 0 & 0.393 \\
Asthma & $2(2.1)$ & 2 & 0 & 0.677 \\
Depression & $2(2.1)$ & 1 & 1 & $>0.999$ \\
HTA & $2(2.1)$ & 0 & 2 & 0.349 \\
Cerebral Infarction & $2(2.1)$ & 1 & 1 & $>0.999$ \\
Venous insufficiency & $2(2.1)$ & 1 & 1 & $>0.999$ \\
Gastroesophageal reflux disease & $2(2.1)$ & 2 & 0 & 0.677 \\
Dilated cardiomyopathy & & & & \\
\hline
\end{tabular}

the use of medical services that are increasingly confronted with the care of the elderly. In our study, the elderly accounted for $17.35 \%$ of patients while the proportion of elderly Beninese was $2.7 \%$ according to the 4 th general population and housing census in 2013 [5]. This figure is close to that obtained in 2012 by Sough et al. in their study on the attendance of the elderly in the emergency room in Macon (France) [6]. This could imply that in Black Africa, the magnitude of health problems of the elderly is a major part of hospital activity and is closer to that of the West.

Almost $90 \%$ of our patients had a known history of chronic disease and a third had at least 3. In Switzerland, Santos-Eggiman finds a little less than $70 \%$ of elderly with at least one comorbidity [6], and Woo in South Korea, a proportion of 78\% [7]. The difference between our results and those of previous authors might be explained by the fact that our study took place in a specialized setting, and most of the patients received were referred from other lower-level hospitals. Therefore, our patients could have more comorbidities than the general population aged 65 and over.

In our work, high blood pressure was the most common antecedent as well as in Hien et al. in Burkina Faso [8]. Sough et al., in France found similar results [9]. Advancing age is believed to be associated with increased comorbidities and arterial hypertension remains the most frequent "silent killer" with high morbidity and mortality [10].

Besides, in our study, cough (11\%) was the most common reason for admission. We do not note a preponderance of any particular type of admission reason. These results contrast with those of Agbodandé et al., who found in Comè (Benin), alteration of general condition as a frequent and dominant reason [7]. Mengue-Me-Mguema had also found at the Gabriel Touré University Hospital in Bamako, a predominant reason for consultation: nontraumatic coma [8]. These differences in the results can be explained by the difference in the me- 
thods. The study by Agbodandé et al. took place in the hospitalization department of Medicine. The study of Mengue-Me-Mguema was in the emergency room and ours took place in consultation. We could deduce that, although the reasons pushing the elderly to consult are very diverse, only a portion of patients with particular clinical situations require hospitalization.

The main nosological groups of pathologies, classified according to ICD 10, were dominated by diseases of the osteo-articular system (17.5\%), followed by diseases of the respiratory system (16.5\%), circulatory system (12.4\%), digestive system (8.2\%), and genitourinary system, tumors (5.2\%). In Tunisia, in a study carried out in the Sousse region, Zedini et al. found, compared to our study, a difference distribution of nosological groups [11]. Cardiovascular pathologies were numerous (26\%), followed by diseases of the respiratory system (20.8\%) and diseases of the osteo-articular system (19.3\%). Cadmus et al. in Nigeria, also found cardiovascular pathologies are also in the first place (48.8\%), followed by bone and joint pathologies [12]. As the large proportion of known hypertensive patients in our study (69\%) would suggest, this is probably not because of a lower prevalence of cardiovascular pathologies in the elderly population in Benin than our figures concerning cardio-related pathologies vascular are lower. The executives used for the various studies could explain these differences. As our study setting is the Internal Medicine department, it is possible that a large number of elderly patients with cardiovascular pathologies would be in the Cardiology department. Cardiovascular disease is on the rise in Benin too. An absence of therapeutic education as well as the insufficiency of strategies for the management of cardiovascular risk factors would explain the increase in these pathologies in our region [13].

The main pathologies found were pneumonia (11.3\%), lumbosacral spondylarthrosis (10.3\%), prostatitis (4.1\%) and asthma (3.1\%). In Sousse in Tunisia, Zedini et al. found arterial hypertension (22.4\%), bronchitis (9.2\%), type 2 diabetes (7.9\%), knee osteoarthritis (4.7\%) and tonsillitis (4.1\%) as the most frequent pathologies. Salvi et al., in India, also found hypertension as the first condition diagnosed in the elderly [14]. The studies by Zedini et al. and Salvi et al. were both done in basic health centers, that is why screening for high blood pressure came first. Pneumonia was the first pathology in our study, while bronchitis came second in Zedini. These figures should be correlated with WHO data, since in 2016 they found respiratory infections as the $4^{\text {th }}$ leading cause of death in the world [15]. Agbodandé et al., had also found that pneumonia represented the second pathology in medical hospitalization in Comè (Municipality of Benin). These points highlight the seriousness of pneumonia and the risk of high morbidity and mortality that the elderly face when they have it. Advanced age over 65 is a criterion for hospitalization for pneumonia. Lumbosacral spondylarthrosis, which has a second place in our study, accounts for $6.7 \%$ of the pathologies found in the elderly in Cadmus in Nigeria. Wong et al., in their review of studies on low back pain and the elderly, had shown that mechanical patholo- 
gies of the lumbar spine were frequent, with a prevalence varying between 12 and 50\% depending on the study population [16].

\section{The Limitations of the Study Are Twofold}

The first limitation is that this study concerns a small population that was received in a non-geriatric specialized service and does not offer a panoramic view of the frequent pathologies of the elderly population in Benin. Geriatric syndromes (mental deterioration, poor physical activity, dizziness/lightheadedness, urinary incontinence, fear of falling/falling) have not been explored. The second major limitation is the retrospective nature of the study.

\section{Conclusion}

Older people are taking an increasing share of society in Black African countries. This category of the population, often with numerous pathologies, explaining the taking of several drugs at the same time, notwithstanding the side effects of these drugs and the weight of the pathologies, has diversified health care needs. It is necessary to work towards the prevention of these pathologies and their consequences on the body and their adequate management.

\section{Conflicts of Interest}

The authors declare no conflicts of interest regarding the publication of this paper.

\section{References}

[1] The World Bank (2018) Life Expectancy at Birth: 1960-2018. The World Bank, Washington DC.

https://donnees.banquemondiale.org/indicateur/SP.DYN.LE00.IN?end=2018\&start $=1960$

[2] United Nations Population Fund (2016) The State of World Population 2016. UNFPA, New York.

https://www.unfpa.org/sites/default/files/sowp/downloads/The State of World Po pulation 2016 - English.pdf

[3] Lévesque, H. (2002) Internist Profession. La Revue de Médecine Interne, 23, 411 414. https://doi.org/10.1016/S0248-8663(02)00587-8

[4] Santos-Eggimann, B. (2007) The Health of People Aged 65-70: A Snapshot Profile. Revue Médicale Suisse, 132, 32660. https://www.revmed.ch/RMS/2007/RMS-132/32660

[5] American Senior Communities (2017) The Top 10 Health Concerns for Seniors. ASC Care, Indianapolis. https://www.asccare.com/health-concerns-for-seniors

[6] Pison, G. (2009) Demographic Ageing Will Be More Rapid in the South than in the North. Population \& Sociétés, 457, 1-4.

[7] Woo, E.K., Han, C., Jo, S.A., et al. (2007) Morbidity and Related Factors among Elderly People in South Korea: Results from the Ansan Geriatric (AGE) Cohort Study. BMC Public Health, 7, 10. https://doi.org/10.1186/1471-2458-7-10

[8] Hien, H., Berthé, A., Koiné Drabo, M., et al. (2014) Prevalence and Patterns of Mul- 
timorbidity among the Elderly in Burkina-Faso: Cross-Sectional Study. Tropical Medicine \& International Health, 19, 1328-1333. https://doi.org/10.1111/tmi.12377

[9] Sough, B., Gauthier, T., Clair, D., et al. (2012) Elders of 75 and over at an Emergency Service. Geriatrie et psychologie neuropsychiatrie du vieillissement, 10, 151 158. https://doi.org/10.1684/pnv.2012.0351

[10] World Health Organization (2013) A Global Brief on Hypertension: Silent Killer, Global Public Health Crisis. WHO, Geneva.

[11] Zedini, C., Ajmi, T.N., Bougmiza, I., et al. (2014) The Morbidity Diagnosed among the Elderly in Primary Care at the Sanitary Region of Sousse. La Tunisie Medicale, 92, 128-134.

[12] Cadmus, E.O., Adebusoye, L.A., Olowookere, O.O., et al. (2017) A Descriptive Study of the Morbidity Pattern of Older Persons Presenting at a Geriatric Centre in Southwestern Nigeria. Nigerian Journal of Clinical Practice, 20, 873-878.

[13] Agbodandé, K.A., Wanvoégbè, F.A., Dodo, L.R.S., et al. (2018) Morbidity and Causes of Death in Elderly Patients Hospitalized at the District Hospital of Comè, Benin. La Revue de Gériatrie, 43, 91-95.

[14] Salvi, S., Apte, K., Madas, S., et al. (2015) Symptoms and Medical Conditions in 204 912 Patients Visiting Primary Health-Care Practitioners in India: A 1-Day Point Prevalence Study (the POSEIDON Study). The Lancet Global Health, 3, e776-e784. https://doi.org/10.1016/S2214-109X(15)00152-7

[15] World Health Organization (2018) The Top 10 Causes of Death. WHO, Geneva. https://www.who.int/fr/news-room/fact-sheets/detail/the-top-10-causes-of-death

[16] Wong, A.Y.L., Karppinen, J. and Samartzis, D. (2017) Low Back Pain in Older Adults: Risk Factors, Management Options and Future Directions. Scoliosis and Spinal Disorders, 12, 14. https://doi.org/10.1186/s13013-017-0121-3 